\title{
KEY FACTORS FOR HASTENING THE STRATEGIC ISSUE DIAGNOSIS PROCESS: A WITHIN ORGANISATIONAL MODEL
}

\author{
JODI A. POTTER \\ JOHN LIPINSKI \\ Robert Morris University
}

\begin{abstract}
Previous research on Strategic Issue Diagnosis (SID) had focused on the complexity and novelty associated with the decision-making process in a turbulent environment. What had not been previously addressed in the extant literature is the requirement for speed inherent within the SID process, especially that is related to the gathering of information and facts through an organisation's environmental scanning procedures. Since proactive management techniques, nimble processes, and systems that allow an organisation to be responsive and build rapid decision-making capabilities are important determinants of success in a turbulent environment, the element of speed associated with SID is an important factor. Our paper identifies a series of propositions focusing attention on elements of the environmental scanning processes and management hierarchies that are intended to counteract the recursiveness and redundancy inherent in SID systems and ultimately hasten the strategic decision-making process.
\end{abstract}

Keywords: Strategic issue diagnosis; environmental scanning and decisionmaking.

\section{INTRODUCTION}

Previous research exists on the strategies used by a firm to obtain competitive advantage in a turbulent environment or an environment characterised by continuous change, uncertainty or complexity. Proactive management techniques, nimble processes, and systems that allow an organisation to be responsive and build rapid decision-making 
capabilities are an important determinant of success in a turbulent environment (Eisenhardt, 1989; Meyers, Goes, \& Brooks, 1993). Strategic issue management (SIM) systems, a popular component of the strategic planning literature for the past two decades, is described as a "real-time" or "online" process whereby the firm develops capabilities to effectively handle discontinuities or crises that occur in its environment (Perrott 1995; Perkins-Munn \& Chen 2004). Issues arise or events occur in the environment that impact the firm's chosen strategic direction. These issue or events can occur rapidly and appear with little warning. They may also occur less quickly, but in small piecemeal parts that individually are not recognised as impactful. However, when pieced together, they represent issues that affect strategy and require a response from the firm. The speed with which the firm is able to interpret and understand the scope and impact of issues through a diagnosis process is a critical component of an effective SIM system.

C) Much of the past literature on SIM systems assumed that issues arise in a coherently complete form that allows for rapid interpretation by the firm's decision makers. Issues arise as weak signals are detected through environment scanning and discontinuities. Although difficult to recognise, they do not arrive as complete surprises. Ansoff, (1991) who initially introduced his concept of SIMS in 1991, advocated processes to assign issues into categories according to required action, outlined "methods for the evaluation, classification and assignment of authority, Presponsibility, and resources necessary to effectively deal with the issues as they arise. Others have focused their efforts on the improvement of traditional strategic planning processes with the incorporation of the principles of issue management (Camillus \& Datta, 1991).

Topologies of SIM systems based on the types of issues that arise or the scope of activities the firm is involved in as it responds to issues have been developed (Dutton \& Ottensmeyer, (1987). Still others have dealt with the diagnosis of strategic issues (Dutton, Fahey, \& Narayanan, 1993). Recently, interest in SIMs and its link to future studies has arisen (Schwarz, 2005). While this research has been an extremely valuable addition to the strategic planning literature, with the exception of Strategic Issue Diagnosis (SID), it has neglected to understand that issues from the environment that rarely arise in a complete format. In a turbulent environment, events are constantly occurring. These events alone may not represent just cause for the firm to alter its strategy, but in various combinations they can develop into issues that require a strategic 
response by the firm. Events may take place over days, weeks, or even months. Piecing together these tidbits of information and formulating them into cohesive strategic issues can incur a considerable degree of time, effort, and interpretation on the part of the firm. Turbulent environments can be characterised by rapid change. A firm that is able to quickly interpret information on events and occurrences and combine these into valid strategic issues will increase its likelihood of successful decision-making in such a fast-paced environment.

Previous work by Dutton et al. (1993) identified a framework designed to increase understanding regarding how organisations diagnose strategic issues. This framework recognises that strategic decisions are indeed messy, and are typically more complex, novel, and open-ended than operational decisions (Ackoff, 1974; Mintzberg, Raisinghani, \& Theoret, 1976; Schwartz, 2005). The authors also took note of the characteristics of strategic issues as being the end-product of ambiguous data and vaguely felt stimuli that has been ordered, explicated, and imbued with meaning. Their framework portrays the inputs, process characteristic, and outputs of strategic issue diagnosis (SID). What the framework does not effectively consider is the characteristics to enhance the speed of diagnosis.

The focus of this paper is on the importance of speed in SID and on understanding which characteristics of the process are required to increase diagnosis speed at the organisational level. Perspectives from competitive response, information processing, organisational learning and decision-making literature are used to build a series of propositions that seek to influence the intrinsically slow characteristics of the SID process. We propose that changes to organisational structure, systems, and style are necessary to increase SID speed and that the necessary components of the process are the development of reliable, relevant, and retrievable information that is managed by knowledgeable, networked, and nimble-minded intelligence professionals whose function is to build cohesive strategic issues from the continuous flow of environmental events that impact the organisation.

\section{STRATEGIC ISSUES}

According to Ansoff (1980) and King (1982), a strategic issue is an event that has a significant performance impact on the firm or one that has 
strategy consequences. As such, the domain subsumed by an issue, especially in its early stages, is likely to be broad, diffused, and illspecified (Dutton et al., 1993). King (1982) also stated that every complex strategic issue can be disaggregated into constituent parts. Logically if we reverse this concept then it is just as likely that disaggregated parts combine to form complex strategic issues. Issues can arise from a number of sources, both internal and external to the firm; however, rarely does a strategic issue arrive on the firm's doorstep in a wholly recognisable form. Information flows into the organisation through many different channels. It arrives as a series of weak signals from a variety of sources. The firms scanning activities are the main tool used to transfer these signals to key decision makers (Heil, Robertson, 1991; Smith \& Grimm, 1991).

-

In today's technologically advanced marketplace, information is plentiful and easy to acquire. Firm's can easily gather information on events that have occurred in their environment. For example, it is relatively easy to acquire details regarding new regulatory changes, competitor actions, or changes in consumer buying preferences. What typically requires -skill, knowledge, and time is assessing and interpreting these events regarding how they impact the organisation and in particular how they might affect strategic decisions now and in the future.

\section{Strategic Issue Management Systems And Strategic Issue Diagnosis}

SIM systems deal with the organisation's capability to manage within a changing environment and minimise the amount of strategic surprises it encounters. SIM systems are designed for use in turbulent environments. According to Ansoff (1991), a turbulent environment is characterised by a high degree of change and unpredictability. SIM systems emphasise concepts like continual surveillance, categorisation of issues according to urgency or potential impact on the organisation, management awareness of important or critical issues, and effective decision-making techniques under times of duress (Ansoff, 1991).

Strategic issue diagnosis is a fluid, emergent, and dynamic process that occurs within a SIM system. It involves dealing with complex, novel, and open-ended decisions that contain interdependent elements (Mintzberg et al., 1976). The focus of SID is on how data and stimuli get interpreted and understood, and the emphasis is upon extensive interaction among decision makers. Dutton et al. (1993) supplied a framework for discussing SID (see Figure 1). 


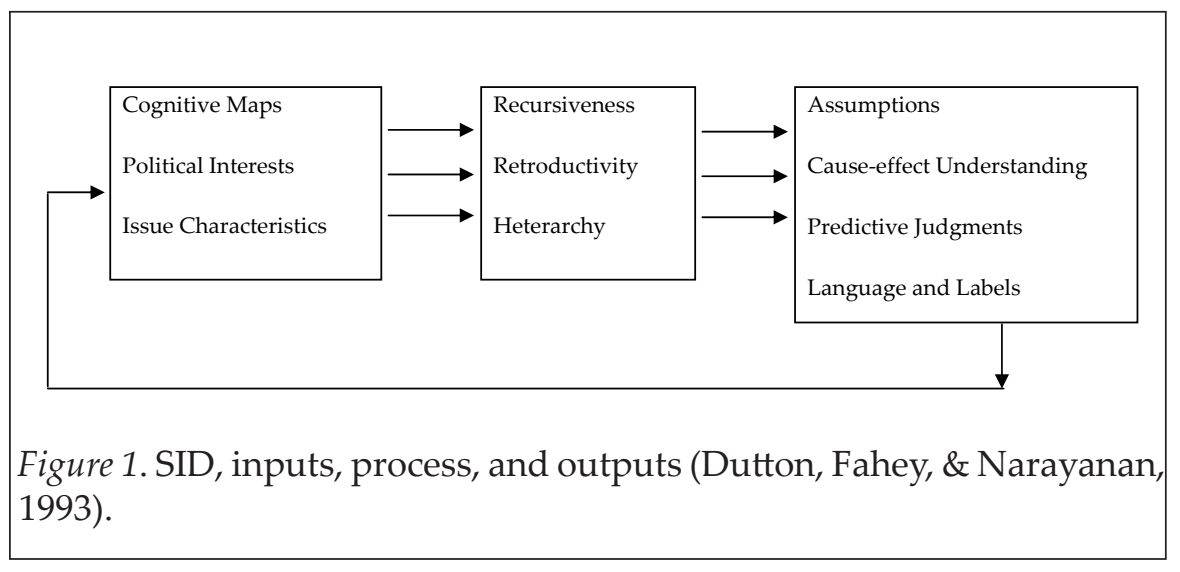

In this model, the authors recognised that strategic issues arise from chaotic and conflicting data that requires some form of interpretive scheme to transform it into usable information. Their framework is comprised of inputs, a process, and outputs of SID. They identified cognitive maps and the political processes of decision makers, along with specific issue characteristics such as important inputs in the altering of data to useful information by individual decision-makers. Cognitive maps represent the beliefs held by an individual, and influence the manner in which he/she assesses and organises issues. Political interests arise due to the importance associated with strategic issues within the organisation, resulting in the development of self-interested behavior in the diagnosis of issues. Finally, issue characteristics influence the diagnosis process since every issue is unique requiring its own resolution process, limiting the firm's ability to use standard templates or familiar routines.

Three process characteristics were also identified by the authors, that of recursiveness, retroductivity and heterarchy. Recursiveness is illustrated by the tendency for the same issue to be redefined several times throughout the decision-making sequence. These revisions reflect the fluidity of participants and available data during the SID process. Data interpretation is not systematic or sequential, new and significant information arrives during all stages of the data evaluation process, thus causing interpretation and search to be interactive.

Retroductivity revolves around issue comprehension and assumes the interaction of both deductive and inductive modes of thinking, which are required for the assessment of strategic issues. Managers rely upon past 
experience and learning to resolve complex issues. They are required to exercise judgment due to a lack of comprehensive data for decisionmaking. Since every decision maker pulls from a diverse and unique set of experiences and learning, multiple decision makers will reduce bias associated with a unilateral approach and this provides a more balance and comprehensive assessment of the issue.

In their discussion on heterarchy, the authors recognised that strategic issues, due to their ability to impact the organisation collectively through a redistribution of key resources, are rarely diagnosed by a single individual; rather a number of individuals from various areas within the organisation assist in the process. This causes the political interests of -individuals within the organisation to be activated and they attempt to use their influence to skew the outputs of the diagnosis in their preferred direction, thus impacting the organisation's ability to achieve consensus and increasing the time required to diagnose the issue.

In the output stage, the diagnosis process generates a set of potentially fluid assumptions required to diagnose the issue, individual judgments surrounding courses of action, different interpretations regarding language and labels applied to the issue, and the understanding of the significance of the issue to the organisation's future success. These outputs serve to impact the organisation beyond the domain of a single

$\infty$ strategic issue.

All of the above descriptions of the stages of issue diagnosis are valid and important concepts associated with a successful SIM system. What is taken into account in the framework is the complexity and "comprehensive impact associated with strategic issues and the types of decision-making characteristic and processes that most adequately manage complex and comprehensive issues. What is not accounted for are characteristics, processes, and the structural requirements designed to promote more rapid dissemination of information to areas within the organisation that require it and increased decision-making speed.

According to Ansoff (1991), when environmental turbulence is at a state where a high speed of change and a low visibility of the future creates a situation in which major discontinuities can surface and impact the firm before strategic planning can determine an effective response. Traditional strategic planning systems are no longer sufficient to assure a timely response. Ansoff had labeled this degree of environmental turbulence 
as level four and five. It is in these environments that real-time or online systems, like SIM systems for strategic response are required (see Figure 2).

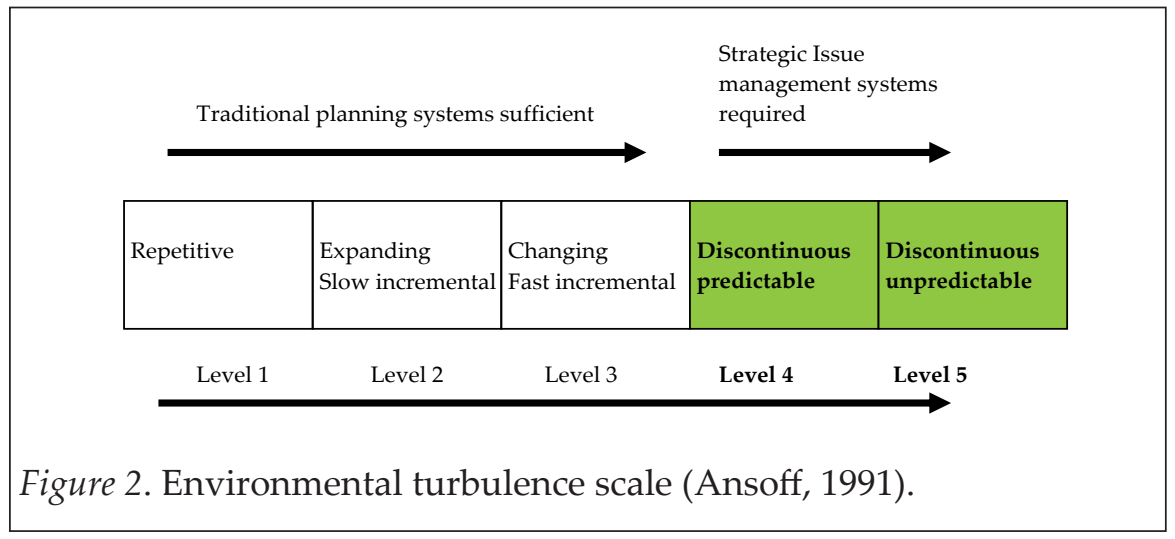

Rapid decision-making capabilities are of interest to decision makers in organisations that operate in turbulent environments where environmental change is frequently occurring. Responding to this change is a necessary component of maintaining a competitive market position or gaining an improved one (Eisenhardt, 1989; Heil \& Robertson, 1991; Smith \& Grimm, 1991). Understanding how to improve the organisation's speed of response is often critical, as response speed or having the flexibility to ensure appropriate timing of a response is a crucial recourse for the organisation or a vital output to be exploited (Gulick, 1987). Increasing the speed of issue diagnosis within SIM systems will in turn increase the organisation's speed of response. In order for SID to be an effective planning tool, the intrinsically slow characteristics of Dutton et al.'s (1993) SID process need to be counteracted with changes in structure, systems, and style that will facilitate more compact timeframes for all aspects of the process.

We propose that the actual process associated with SID involves three key phases: information gathering, information processing, and a choice activity. These are common phases across many different models associated with competitive response, information processing decisionmaking systems. Within all of these theories there exists some focus on the perceived benefits of speed. The SID process, due to its use in turbulent environments characterised by rapid and discontinuous change, would benefit from an increased understanding of key factors that would enhance diagnosis speed. 


\section{INFORMATION GATHERING}

The concepts upon which SID processes are based are closely related to the competitive response processes (Hahn, 1991). Competitive response routines provide firms with unique capabilities regarding the gathering of information that is used to identify issues or opportunities. Competitive response is also concerned with timing. Scholars have argued that the timing of a response is crucial to the competitive advantage of both the acting and responding firm. The theory holds that acting firms take advantage of time lags between action and reaction by competitors. The acting firm can earn abnormal positive returns due to its monopolistic position prior to a rival's response (Lieberman \& Montgomery, 1988; Nelson \& Winter, 1982.)

$\square$

In a competitive response situation, this first step of intelligence gathering can be more specifically defined as analysis of the current situation or retrieving and organising the information regarding a rival's move. This C) typically requires data gathering from both external and internal sources in order to ensure that a complete understanding of the rival's move and its impact on the organisation are clearly ascertained. This step can be relatively simple or more difficult to achieve, depending upon how much information is deemed to be important to the decision process. This is similar to SID processes where the volume of information can influence both the quality and speed of issue diagnosis. Decision makers who gather extensive information tend to have more accurate perceptions Oof environmental conditions (Bourgeois, 1985) and fast decision makers actually use more information not less (Eisenhardt, 1989).

According to Eisenhardt (1989), the critical distinction lies with the type nof information that decision makers focus on rather than the volume of information available and utilised. Slow decision makers rely on planning and futuristic information, and spend time trying to track the paths of technology and markets and then develop their plans. Fast decision makers rely upon real-time information and focus on what is happening in the present rather than relying heavily on past or future considerations. Therefore, utilising a large volume of coherent information can be supportive to the overall decision process, certainly if the information is real-time, factual, relevant to the decision and readily available or easily retrieved.

Proposition \#1: The greater the focus on the use of real-time information and facts gathered from present environmental events, the more rapid will the be decision-making associated with SID. 
The process of choice or decision-making is also one that is directly related to SID processes. The first activity associated with decisionmaking is intelligence gathering which is environmental scanning and involves gathering and processing information (March \& Simon, 1958; Simon, 1960). Scanning is the first step in organisations adapting to their environment (Child, 1972; Daft \& Weick, 1989). Environmental scanning is an important process associated with the gathering of information and can increase performance in turbulent environments. In uncertain environments, chief executives of high performing companies report to scan more broadly and more frequently (Xu, Kaye, \& Duan, 2003). They directed their scanning efforts to sectors where the greatest amount of uncertainty existed and relied heavily on scanning from both internal and external sources.

Thomas (1980) identified different scanning intensities; irregular, regular, and continuous. The method chosen is was determined by the content required, the time available, and the space (size) of the end user. Content consists of scope, range, and futurity. Organisations with information needs are were characterised by a broader continuum, global perspective, and a high degree of interest in long-term future events. On the opposite end of the scale, organisations with information needs characterised by a narrow continuum, localised perspectives, and low interest in predicting future events are irregular and less frequent in their scanning activities. Environments that are unpredictable and have rapid continuous change would require continuous scanning since irregular or regular scanning activities would not provide sufficient information regarding occurrences or events. Therefore SID, being a process that is designed to operate in a turbulent environment, would benefit from frequent environmental scanning.

Proposition \#2: The frequency and quality of an organisation's environmental scanning processes will have a direct effect on the speed and quality of information obtained for the purposes of SID.

The boundary of an organisation is the region between one system and another that regulates the flow of information, material, and people into and out of the system (Leifer \& Delbecq, 1978). Individuals who operate within this region, relating the organisation to its environment, are called boundary spanners. They summarise information about the intention and significance of competitive action and communicate this information through internal organisational channels to decision makers. A typical example of boundary spanning personnel is a marketing or sales force; however, any member of the organisation who interacts directly with the market can be a boundary spanner. Organisations with more 
boundary spanning personnel are more likely and capable of receiving and assessing information on competitive actions, thus allowing them to respond faster (Smith \& Grimm, 1991).

Proposition \#3: The more an SID process makes use of boundary spanners for the purpose of environmental scanning, the greater the likelihood that timely and comprehensive information necessary for the purposes of issue diagnosis will be available.

In many cases boundary spanners are unaware of their significant contribution to the environmental scanning process. They perceive their functionality to revolve around the role they formally play within the organisation. If they are made aware of the importance of their ability to acquire unique environmental data that the organisation would have difficulty obtaining elsewhere, they can play a vital and irreplaceable role in the manner in which an organisation obtains information. This acknowledgement not only requires recognition by the organisation regarding their role; it requires a destination for the information they retrieve.

\section{INFORMATION PROCESSING}

The second phase of Simon and March's decision-making model is the design activity phase which is described as the process where decision makers analyse the formulated alternatives to determine outcomes that satisfy the needs and objectives of the organisation (March \& Simon, 1958; Simon, 1960). Within the SID process, this is where the gathered information is transformed through the expertise of the process participants into relevant information. An important component of this process is ensuring that the information used is easily retrieved by the decision makers. Ensuring the relevance and retrievability of information can involve changes in organisational structure to build better communication channels across organisational boundaries and systems that support the storage, manipulation, and availability of information.

Information processing in organisations is generally defined as the gathering of data, transforming that data into information, and then either immediately communicating it, or storing the information for future use (Galbraith, 1973; Tushman \& Nadler, 1978). Organisations of varied size or structure carry out this function in many different ways, resulting in many levels of success or failure associated with this activity. Information processing is an integral part of SIM and more directly, SID. A significant amount of literature that exists on information processing 
within organisations explores how the degree of uncertainty an organisation is faced with impacts its structure (Egelhoff, 1991). Galbraith (1973) defined the relative information-processing capacities of different organisational designfeatures, identifying them as rules and programmes, hierarchical referral, goal-setting, vertical information systems, and lateral relations. When the environment for decision-making is stable and simple, standard rules and programmes are sufficient to handle the small amount of uncertainty the organisation is exposed to. When uncertainty increases, decisions are referred up the corporate ladder or the hierarchical authority structure. When the information-processing requirements threaten to overload senior management, goal setting and planning helps to facilitate more decision making at lower levels as long as they are following the plan. Vertical information-processing systems like computer based information systems, databases, and staff groups increase the capacity for centralized information processing and alleviate pressure on the hierarchical structure. When uncertainty and information-processing requirements are at their peak, lateral relation mechanisms like direct contact between individuals, liaison roles, task forces, teams, and matrix designs help to support the organisation and allow it to retain its effectiveness.

Ansoff (1991) suggested that SIM would apply at what he defined as level four environmental turbulence. The characteristics of level 4 turbulence are similar to those identified by Galbraith (1973) where the use of vertical information processing systems and lateral relation mechanism assist in the organisation's ability to process information (see Figure 3).

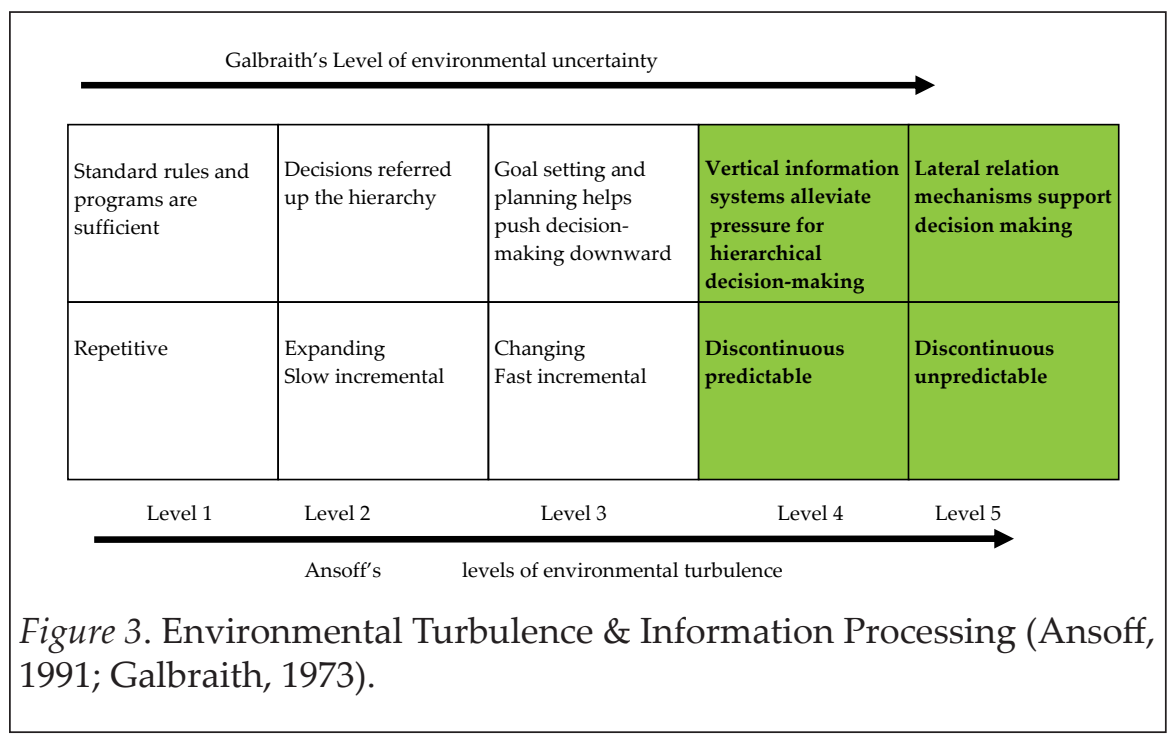


When an environment is characterised by only partial future predictability, evolution of challenges more rapid than firm responses, discontinuous and unfamiliar events, and a high level of complexity, SIM systems and therefore SID are necessary for the planning process to be successful. Galbraith (1973) suggested that in similar environments, vertical information systems can alleviate the pressure for hierarchical decision-making and lateral relation mechanisms can support decisionmaking and reduce its timeframe. Therefore if in SID, the nature of strategic issues drives recursiveness, retroductivity, and heterarchy into the process of diagnosis and impede the firm's ability to formulate strategic decisions; inserting vertical information systems and building lateral relation mechanisms into the SID process should seek to alleviate the firm's reliance on these intrinsically slow decision-making characteristics.

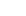

Galbraith's (1973) model provides an operational framework for linking the degree of uncertainty an organisation faces with an organisational design feature or mechanism. The better the fit between the two, the Dmore successful the organisation is at processing timely and accurate information. These information processing mechanisms or tools can be categorised into those that are routine, (i.e., address inputs that are frequent and homogenous), and those that are non-routine (i.e. pertain to unique, infrequent, and heterogeneous inputs) Daft \& Macintosh 1981; Daft \& Weick, 1989). Examples of mechanisms most apt to process routine information are standard corporate rules and regulations, single „cycle planning systems, and most computer based information systems. 10 Non-routine information due to its increased level of uncertainty and differentiation from standard information requires more specialised or unique mechanisms like task forces and teams, matrix organisational designs, and interactive planning systems. Increases in environmental uncertainty also lower the quality of information available to managers, "hampering their ability to forecast sales and earnings streams. With lower quality information, errors in decision-making are more likely to occur (Galbraith, 1973; Lawrence \& Lorsch, 1967). This being the case, the more an organisation is able to reduce the uncertainty it faces, the more easily and accurately it should be able to process decisions. Therefore if relevant information is comprehensive and readily available, it should serve to increase the speed of decision making.

Galbraith (1973) categorised most computer based information systems as a mechanism most apt to process routine information, and undoubtedly at the time he arrived at this conclusion, that was a valid assumption. However today, computer databases or information management systems are able to handle a variety of information types, both routine and non-routine. As outlined by the financial executive institute: 
Technology proficient companies have the bulk of their executives gaining access to information on-line, making extensive use of executive information systems to aid their decision making. The best can readily slice and dice information, reporting across multiple dimensions, such as geography, product, commodity, customer, supplier or major project (Galbraith, 1973).

Boundary spanning personnel require a destination for their gathered information and a medium for it to be assimilated into the organisation. Adequately capturing the volume of information that can be gathered by a large number of boundary spanning personnel presents difficulty associated with information overload for the organisation. Interpretation is less effective if the information to be interpreted exceeds the ability to process the information adequately (Huber, 1991). Simon (1973) suggested that firms operating in information rich environments should seek to minimise the distribution of information across business units.

As recognised by Huber (1991) this design for informational autonomy reduces information sharing across the organisation and curtails some types of organisational learning. The solution appears to be one that reduces the potential for overload without reducing the relevance of the information, and allows for easy dissemination throughout the organisation on an as-needed basis. A process to filter the information with the intent of organising it in a manner that reduces its ambiguity and complexity is necessary, as well as a process for storing and retrieving the information when it is required. As a result of specialisation, differentiation, and departmentalisation, organisations frequently do not know what they know. Computer information systems have the potential to reduce this problem due to their ability to store and manipulate vast amounts of data and information.

What is readily available or already known about a strategic issue should facilitate a reduction in the amount of inherent uncertainty management faces and thus reduce the time required for a strategic decision. Since strategic issues rarely arrive in a single recognisable form, a database would provide the benefit of storing, retrieving, and combining environmental events, signals, and market occurrences. Simon (1987) argued that the essence of intuition lies in the organisation of knowledge for quick identification. He was referring to the human mind, but the underlying principal of organising vast amounts of information for rapid recognition is the basis for the concept of an information computer database. You would expect that a wellmaintained and up-to-date information database would facilitate the 
organisation's ability to recognise strategic issues since it would store historical data and allow for the manipulation of both newly retrieved and historical data into coherent intelligence. In addition, the building blocks for the development of a strategic issue could exist and be located in the database, and therefore much of what is required to be processed by decision-makers might already be in existence, able to be easily accessible by key decision makers, and perhaps already ingested, and recognised as facts by the management.

Proposition \#4: The more an organisation makes use of up-to-date information databases that allow for the ongoing storage and rapid manipulation of environmental events, the faster it will be able to diagnose strategic issues.

Likewise, having a single group of knowledgeable intelligence experts whose function is to accumulate and filter the high volume of information coming from boundary spanners would also increase speed within the SID process. These individuals would be at the forefront of the organisation learning process. Crossan, Lane, and White (1997) provided a unifying framework for organisational learning that outlines three different levels of learning; individual, group, and organization (see Table 1); "Organisational learning is the process of change in individuals and shared thought and action, which is affected by and embedded in the institutions of the organisation."

Table 1

Crosson, Lane, and White's Unifying Framework for Organisational Learning (1997)

Level Process Inputs / Outcomes

\begin{tabular}{|c|c|c|}
\hline & Intuiting & $\begin{array}{l}\text { Experiences } \\
\text { Images } \\
\text { Metaphors }\end{array}$ \\
\hline Individual & Interpreting & $\begin{array}{l}\text { Language } \\
\text { Cognitive Map } \\
\text { Conversation / Dialogue }\end{array}$ \\
\hline Group & Integrating & $\begin{array}{l}\text { Shared understading } \\
\text { Mutual adjustment } \\
\text { Interactive systems }\end{array}$ \\
\hline Organisation & Institutionalising & $\begin{array}{l}\text { Plans / routines / norms } \\
\text { Diagnostic systems } \\
\text { Rules \& procedures }\end{array}$ \\
\hline
\end{tabular}


Four basic processes link their three levels of learning; intuiting, interpreting, integrating, and institutionalising. Intuiting is a subconscious process that is the start of learning and happens within a single mind. Interpreting recognises this learning and shares it at the group level. Integrating is when learning changes the collective understanding at the group level and moves toward the organisational level. Institutionalizing flows the learning across the organisation by embedding it in routines, systems, plans, and practices.

Combining events into strategic issues is a learning process. It involves both tacit and explicit knowledge. It begins at the individual level and then is transferred to the sector of the organisation that requires it. Intelligence experts would rely upon their own cognitive maps and mental models to recognise key triggers for the combining of events into strategic issues. At the same time, they will also rely upon an extensive network of contacts from both within and outside the firm to deepen and broaden the perspective they gain from the information gathered. They would also carefully monitor the environment, seeking cues to refine their understanding of a situation or event. In this way they would interpret the information they received and then integrate it through the shared understanding and mutual adjustments that would occur during their discussion with their network of contacts. It is their function to assimilate the piecemeal barrage of events, signals, and occurrences into the initial form of strategic issues.

Intelligence experts' role would be to maintain the information database and provide primary support to key decision makers when an environmental event occurs or when a strategic issue requires action. This would also increase the organisation's SID speed by reducing the recursiveness and retroductivity of the process. Key resources would be immediately available, and the intelligence experts could provide expertise and experience in evaluating an event and in determining strategic issues, thus reducing the organisation's desire to continually reassess the meaning of a strategic issue. Cohen and Levinthal (1990) discussed the importance of a firm's ability to exploit external knowledge as a critical component of innovative capabilities. They argued that prior related knowledge confers an ability to more readily recognise the value of new knowledge, assimilate it and apply it for the best use within the organisation. They defined this ability as an organization's absorptive capacity.

Galbraith (1973) emphasised structural characteristics of high participation and interaction and low levels of formalisation to facilitate 
a high level of information processing. These individual intelligence experts would stimulate ongoing discussion and interaction regarding environmental events. They could provide timely and relevant information to support decision making, but do so in an efficient and nimble manner by interjecting themselves in and out of the process on an as-needed basis. Based on their ability to reduce recursiveness and retroductivity in the SID process and their focus on instilling ongoing interaction and nimble support to decision makers, it seems logical that the following will hold true:

Proposition \#5: The presence of a dedicated intelligence group, as a primary point of contact for boundary spanners and key decision makers, whose function involves intuiting, interpreting, and integrating organisational learning, -will increase the organisation's capacity for ongoing centralised information processing and thus speed up SID.

These intelligence personnel would need to be recognised as credible (1) and influential at the organisational decision-making level, since the only -relevant learning that occurs in an organisation is by those who have the power to act upon it (deGeus, 1988). The reputation they hold would be an important criterion for their ability to influence decision makers and reduce the amount of retroductivity inherent in the SID process. Krepps (1990) defined reputation as "a perceptual representation of a company's past actions and future prospects that describe the firm's overall appeal "to all its key constituents when compared to other leading rivals". He Suggested it is a signal of quality and identifies reputation efficiencies as reduced monitoring and increased influence. Their network is also important to the development of their reputation as knowledgeable and reliable purveyors of strategic issue information. Networks can provide "knowledge, resources, reputation, and market power in an industry (Ingram \& Baum, 1997).

Proposition \#6a: Utilisation of a network of contacts for the purpose of improved recognition of strategic issues and determination of their impact on the organization will enhance a dedicated intelligence group's reputation for the provision of relevant and reliable information.

Proposition 6b: A reputation for being credible will impact a dedicated intelligence group and its ability to more rapidly influence key decision makers, thus reducing the time required for SID.

Strategic issue recognition is an immensely complex process involving the intuiting and interpreting of massive amounts of detail. It involves 
learning in the form of fits and starts, discoveries based on serendipitous events and the recognition of unexpected patterns. This process requires insight, creativity, and synthesis. An individual's cognitive ability and use of intuition will likely influence their pace of strategic decision making. These character traits will also influence the manner in which an individual processes information and generates relevant intelligence and critical components of SID. Cognitive ability is the levels of intellectual ability brought to decision making and manifest itself in an individuals' cognitive complexity and information processing skills (Hitt \& Tyler, 1991). The ability to process numerous alternatives cognitively and simultaneously, a form of cognitive ability, expedites the pace of strategic decision making (Wally \& Baum, 1994) and likewise the pace of SID.

Intuition is an unconscious ability to efficiently sort, code, and access meaningful and relevant decision outcomes from past experiences (Agor, 1989). In this manner intuition is the ability to learn from past experiences and draw upon a base of stored knowledge when necessary. This is the intuiting process defined by Crossan et al (1997). Intuition can speed up the process of SID through providing cognitive maps effective for the categorisation and understanding of environmental events.

Proposition 7a: The greater a decision-maker's cognitive ability; the more rapidly he/she is able to process vast amounts of detailed information for the and diagnosis of strategic issues.

Proposition 7b: The greater a decision-maker's use of intuition, the more rapidly he/she is able to ascertain the significant components within detailed information for the diagnosis of

strategic issues.

\section{CHOICE ACTIVITY}

The final activity associated with decision making is the choice activity. This is when decision makers make judgments and choose among the outlined alternatives (March \& Simon, 1958; Simon, 1960). It is the part of the process where relevant information is transferred to decision-makers for interpretation and integration. An important aspect of this process is the achievement of common goals and understanding regarding strategic direction, the format for the manner in which information is transferred, and the structure of the decision-making process. 
It is important that information or data is organised into a format that is easily understood and manipulated by key decision makers. The intent here is to package the information in a manner that evokes acceptance of the content, achieves objectivity in its display, and provides the important results from the data gathering phase (Elsbach \& Elofson, 2000). The organisation then moves onto trying to decide what an effective response would be. This is the complex part of the process and initially involves sharing the information with all of those engaged in the decision-making process. This step of information sharing is intuitively contained within March and Simon's design activity phase, but is not specifically emphasised. Information sharing, while seemingly a simple task, can involve a high degree of an organisation's time and energy. It can be completed in a cost effective, accurate and timely manner, or -entail a significant amount of the decision time. The ability for a firm to

recognise the value of new external information, assimilate it, and apply it to commercial ends is critical to its innovative capabilities (Cohen \& Levinthal, 1990).

(1)

Structural complexity refers to the number of levels that information must travel through in order to reach the key decision makers. As structural complexity within the organisation increases, so does the chance that the information regarding a rival's action will be altered or blocked (Smith \& Grimm, 1991). Therefore in a hierarchical organisation comprised of many different decision levels, the propensity for the information -gathered to be less complete or valuable by the time it reaches the correct Dparty is increased. This would obviously slow down the organisation's ability to formulate a response since information that is incomplete or seemingly inaccurate would require both additional data gathering and information sharing to correct the problem.

-

Flat organisational structures offer the benefits of reduced hierarchy due to the existence of less management levels within their structure. It is known that organisations with concentrated power produce faster strategic decisions because fewer people are involved in the process, reducing conflict, and the need for information sharing and consensus seeking (Pfeffer, 1981). The process of SID would occur more rapidly in organisations with management structures that are non-hierarchical, since there exists an improved possibility that reliable, relevant, and timely information will be used in decision making and that heterarchy will be reduced.

Proposition 8: The flatter the organisational structure, the less structural complexity and the more rapid will be the process of SID. 


\section{IMPLICATIONS FOR MANAGERS}

Over the years, the body of work associated with strategic issue management has grown. The primary functions of association with SIM systems are recognised as important for effective decision making in turbulent environments (Ansoff, 1991; Eisenhardt, 1989). Further research into SIM systems and SID, particularly exploring the speed at which managers are able to make decisions, will influence activities related to competitive response, information processing, and organisational learning. In business, the importance of speed at which one processes information has increasingly become not only a key advantage, but a requirement for survival. Helping managers to process information and disseminate it through their organisations more quickly will continue to provide key advantages. Testing our propositions will allow systems to be developed that will facilitate more efficient use and distribution of information, and lead to more timely and accurate strategic decisions.

\section{CONCLUSION}

In this paper, we have developed a model and proposed a framework to extend the traditional planning system with SID. Rapid decision-making capabilities are of interest to decision makers in organisations, especially in turbulent environments. Proactive management techniques, nimble processes, and systems that allow an organisation to be responsive and build rapid decision-making capabilities are an important determinant of success in a turbulent environment. Our paper has developed testable propositions that can be explored in testing SIM and SID systems, and will lead to methods that will allow companies to handle information more quickly and efficiently. Speed in these areas will help companies develop and maintain a competitive advantage with regard to their knowledge management and decision-making processes.

\section{REFERENCES}

Ackoff, R. A. (1974). Redesigning the future. NY: Wiley.

Agor, W. H. (1989). Intuition in organisations. Newbury Park, CA: Sage.

Ansoff, I. H.(1980). Strategic issue management. Strategic Management Journal, 2(1), 131-148.

Ansoff, I. H. (1991). Strategic management in historical perspective. International Review of Strategic Management, 2, 449-461. 
Bourgeois, L. (1985). Strategic goals, perceived uncertainty, and economic performance in volatile environments. Academy of Management Journal, 28, 548-573.

Camillus, J. C., \& Datta, D. K. (1991). Managing strategic issues in a turbulent environment. Long Range Planning, 17, 17-24.

Child, J. (1972). Organization structure, environment, and performance: The role of strategic choice. Sociology, 6, 2-22.

Cohen, W., \& Levinthal, D. (1990). Absorptive capacity: Anew perspective on learning and innovation. Administrative Science Quarterly, 35, 128-152.

Crossan, M., Lane, H., \& White, R. (1997). Organizational learning: Toward theory. Working Paper (London, Ontario: Richard Ivey School of Business, University of W. Ontario).

"Daft, R. L., \& Macintosh, N. B. (1981). A tentative exploration into the amount of information processing in organisational work units. Administrative Science Quarterly, 26, 207-224.

Daft, R. L., \& Weick, K. E. (1989). Toward a model of organisations as interpretation systems. Academy of Management Review, 9, 248-295.

deGeus, A. P. (1988). Planning as learning. Harvard Business Review, 66, 70-74.

Dutton, J. E., Fahey, L., \& Narayanan, U. K. (1993). Toward understanding strategic issue diagnosis. Strategic Management Journal, 4, 307-323.

Dutton, J. E., \& Ottensmeyer, E. (1987). Strategic issue management systems: Forms, functions and contexts. Academy of Management Review, 12, 355-365.

Eisenhardt, K. M. (1989). Making fast strategic decisions in high-velocity environments. Academy of Management Journal, 32, 543- 558.

Egelhoff, W. (1991). Information processing theory and the multinational enterprise. Journal of International Business Studies, 3rd Quarter, 341368.

Elsbach, K., \& Elofson, G. (2000). How the packaging of decision explanations affects perceptions of trustworthiness. Academy of Management Journal, 43, 80-93.

Galbraith, J. (1973). Designing complex organisations. Reading, MA: Addison-Wesley.

Gulick, L. (1987). Time and public administration. Public Administration Review, 47, 115-119.

Hahn, D. (1991). Strategic management - tasks and challenges in the 1990s. Long Range Planning, 24(1), 26-39.

Heil, O., \& Robertson, T.S. (1991). Toward a theory of competitive market signaling a research agenda. Strategic Management Journal, 12, 403418. 
Huber, G. P. (1991). Organisational learning: The contributing processes and the literatures. Organisation Science, 2, 88-115.

Hitt, M. A., \& Tyler, B. B. (1991). Strategic decision models: Integrating different perspectives. Strategic Management Journal, 12, 327-351.

King, W. R. (1982). Using strategic issue analysis. Long Range Planning, 15, 45-49.

Krepps, D. L. (1990) Corporate culture and economic theory. In Alt, J. E., \& Shipsle, K.A. (Eds.) Perspectives on positive political economy. Cambridge: Cambridge U. Press.

Lawrence, P. R., \& Lorsch, J. W. (1967). Organisation and environment. Boston: Harvard Business School Press.

Leifer, R., \& Delbecq, A. (1978) Organizational/environmental interchange. Academy of Management Review, 3, 40-50.

March, J. G., \& Simon, H. A. (1958). Organisations. New York: Wiley. Mintzberg, H., Raisinghani, D., \& Theoret, A. (1976). The structure of unstructured decision processes. Administrative Science Quarterly, 21, 246-275.

Perkins-Munn, T. S., \& Chen, Y. T. (2004). Streamlining project management through online Solutions. Journal of Business Strategy, 25(1), 45-48.

Perrott, B. (1995). Strategic issue management: An integrated framework. Journal of General Management, 21(2), 52-63.

Pfeffer, J. (1981). Power in organizations. Cambridge, MA: Ballinger.

Simon, H.A. (1960). The new science of management decision. New York: Harper \& Row.

Simon, H.A. (1973). Applying information technology to organisational design. Public Administration Review, 33, 268-273.

Simon, H.A. (1987). Making management decisions: The role of intuition and emotion. Academy of Management Executives, 1, 57-64.

Sinclair, G., Klepper, S., Cohen, W. (2000). What's experience got to do with it? Sources of cost reduction in a large specialty chemicals producer. Management Science, 46, 28-45.

Smith, K., \& Grimm, C. (1991). A communication-information model of competitive response timing. Journal of Management, 17, 5-23.

Teece, D., Pisano, G., \& Shuen, A. (1997). Dynamic capabilities and strategic management. Strategic Management Journal, 18, 509-533.

Tushman, M., \& Nadler, D. A. (1978). Information processing as an integrating concept in organizational design. Academy of Management Review, 3, 613-24. 
Wally, S., \& Baum, R. (1994). Personal and structural determinates of the pace of strategic decision making. Academy of Management Journal, 37, 932-956.

Xu, X. M., Kaye, G.R., \& Duan, Y. (2003). UK executives' vision on business environment for information scanning: A cross industry study. Information and Management, 40, 5, 381-389. 